\title{
Drug Distribution into Peripheral Nerve ${ }^{[}$
}

\author{
Houfu Liu, Yan Chen, Liang Huang, Xueying Sun, Tingting Fu, Shengqian Wu, Xiaoyan Zhu, \\ Wei Zhen, Jihong Liu, Gang Lu, Wei Cai, Ting Yang, Wandong Zhang, Xiaohong Yu, \\ Zehong Wan, Jianfei Wang, Scott G. Summerfield, Kelly Dong, and Georg C. Terstappen
}

Department of Mechanistic Safety and Disposition (H.L., X.S., T.F., S.W.), Bioanalysis, Immunogenicity and Biomarkers (L.H., X.Z., K.D.), Integrated Biological Platform Sciences (Y.C., We.Z., J.L., J.W.), Brain Delivery Technologies (Wa.Z.), Platform

Technology and Science (G.C.T.), and Department of Neuroexcitation Discovery Performance Unit (G.L., W.C., T.Y., X.Y., Z.W.), GlaxoSmithKline R\&D, Shanghai, People's Republic of China; and Department of Bioanalysis, Immunogenicity and Biomarkers, Platform Technology and Science, GlaxoSmithKline, Ware, United Kingdom (S.G.S.)

Received October 10, 2017; accepted March 1, 2018

\begin{abstract}
Little is known about the impact of the blood-nerve barrier (BNB) on drug distribution into peripheral nerves. In this study, we examined the peripheral nerve penetration in rats of 11 smallmolecule drugs possessing diverse physicochemical and transport properties and ProTx-II, a tarantula venom peptide with molecular mass of 3826 Daltons. Each drug was administered as constant rate intravenous infusion for 6 hours (small molecules) or 24 hours (ProTx-II). Blood and tissues including brain, spinal cord, sciatic nerve, and dorsal root ganglion (DRG) were collected for drug concentration measurements. Unbound fractions of a set of compounds were determined by equilibrium dialysis method in rat blood, brains, spinal cords, sciatic nerves, and DRG. We also investigated the influence of $N$-[4-[2-(6,7dimethoxy-3,4-dihydro-1H-isoquinolin-2-yl)ethyl]phenyl]-5methoxy-9-oxo-10H-acridine-4-carboxamide (GF120918), a
\end{abstract}

P-glycoprotein (P-gp) and breast cancer resistance protein (BCRP) inhibitor, on the peripheral nerve and central nervous system (CNS) tissue penetration of imatinib. We found that: 1) the unbound fraction in brain tissue homogenate highly correlates with that in the spinal cord, sciatic nerve, and DRG for a set of compounds and thus provides a good surrogate for spinal cord and peripheral nerve tissues, 2) small-molecule drugs investigated can penetrate the DRG and sciatic nerve, 3) P-gp and BCRP have a limited impact on the distribution of small-molecule drugs into peripheral nerves, and 4) DRG is permeable to ProTx-II, but its distribution into sciatic nerve and CNS tissues is restricted. These results demonstrate that small-molecule drugs investigated can penetrate peripheral nerve tissues, and P-gp/BCRP may not be a limiting factor at the BNB. Biologics as large as ProTx-II can access the DRG but not sciatic nerve and CNS tissues.

\section{Introduction}

Peripheral nerves transmit impulse signals from the periphery to the central nervous system (CNS) or from the CNS to the periphery, which is crucial for normal human sensory and motor function. To ensure the proper function of peripheral nerves, maintenance of homeostasis is required for the endoneurial environment, which is endowed by the presence of the blood-nerve barrier (BNB). The BNB is located at the innermost layer of the investing perineurium and at the endoneurial microvessels within the nerve fascicles in the peripheral

This study was supported financially by GSK.

https://doi.org/10.1124/jpet.117.245613.

S This article has supplemental material available at jpet.aspetjournals.org. nerve system (Bell and Weddell, 1984; Weerasuriya and Mizisin, 2011; Kanda, 2013). Tight junctions between endothelial cells and between pericytes in endoneurial vasculature isolate the endoneurium from the blood, thus preventing uncontrollable leakage of molecules and ions from the circulatory system to the peripheral nerves (Peltonen et al., 2013).

In addition, there exists a diffusion barrier within the perineurium formed by tight junctions between the neighboring perineurial cells and basement membranes surrounding each perineurial cell layer. Evidence from various physiologic and morphologic studies indicates that blood-nerve substance exchange occurs predominantly through endoneurial capillaries and that perineurial passage constitutes a minor route (Rechthand et al., 1988; Weerasuriya and Mizisin, 2011). The two restrictive barriers separate the endoneurial extracellular

ABBREVIATIONS: BBB, blood-brain barrier; BCRP, breast cancer resistance protein; BNB, blood-nerve barrier; BSCB, blood-spinal cord barrier; CNS, central nervous system; DMSO, dimethylsulfoxide; DRG, dorsal root ganglion; GF120918, N-[4-[2-(6,7-dimethoxy-3,4-dihydro-1Hisoquinolin-2-yl)ethyl]phenyl]-5-methoxy-9-oxo-10H-acridine-4-carboxamide; $f_{\mathrm{u}}$, unbound fraction; $f_{\mathrm{u}, \mathrm{b}}$, unbound fraction in blood; $f_{\mathrm{u}, \mathrm{br}}$, unbound fraction in brain; $f_{\mathrm{u}, \mathrm{sc}}$, unbound fraction in spinal cord; $f_{\mathrm{u}, \mathrm{drg}}$, unbound fraction in dorsal root ganglion; $f_{\mathrm{u}, \mathrm{sn}}$, unbound fraction in sciatic nerve; $K_{\mathrm{p}}$,

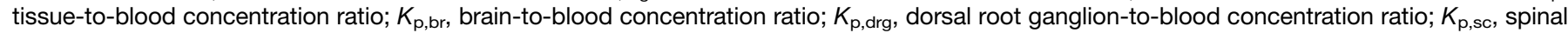
cord-to-blood concentration ratio; $K_{\mathrm{p}, \mathrm{sn}}$, sciatic nerve-to-blood concentration ratio; $K_{\mathrm{p} \text {,uu }}$, tissue-to-blood unbound concentration ratio; Ko143, (3S,6S,12aS)-1,2,3,4,6,7,12,12a-octahydro-9-methoxy-6-(2-methylpropyl)-1,4-dioxopyrazino[1', '2':1,6]pyrido[3,4-b]indole-3-propanoic acid 1,1dimethylethyl ester; LY335979, (R)-4-[(1aR,6R,10bS)-1,2-difluoro-1,1a,6,10b-tetrahydrodibenzo-(a,e)cyclopropa(c)cycloheptan-6-yl]- $\alpha$-[(5-quinoloyloxy)methyl]-1-piperazine ethanol trihydrochloride; PBS, phosphate-buffered saline; P-gp, P-glycoprotein; UPLC, ultraperformance liquid chromatography. 
environment of peripheral nerves from both the epineurial perifascicular space and the systemic circulation, thus protecting the endoneurial microenvironment from drastic concentration changes in the vascular and other extracellular spaces.

For drug targets located in peripheral nerves, the BNB can be problematic because of the potential to restrict or prevent drugs from reaching their site of action, thus negatively affecting drug efficacy. Previous studies indicate that the distal trunks of peripheral nerves (e.g., sciatic nerve) are relatively impermeable to hydrophilic small molecules such as sucrose (Rechthand et al., 1987), fluorescein (Abram et al., 2006), and also large molecules (Poduslo et al., 1994) due to the limited intercellular diffusion. In addition, transporter expression profiles in peripheral nerves can be very different from those in the CNS (Allt and Lawrenson, 2000). For instance, P-glycoprotein (P-gp) and breast cancer resistance protein (BCRP) do not have an appreciable impact on drug distribution into sciatic nerves, as indicated by the comparable sciatic nerve to plasma concentration ratios between wild-type and transgenic knockout rats for several P-gp and/or BCRP substrates (Huang et al., 2015). This is distinct from the CNS where P-gp and BCRP are two key gatekeepers preventing drug distribution into the brain (Schinkel et al., 1996; Liu et al., 2017). Interestingly, drug passage into the cell body-rich dorsal root ganglion (DRG), which is part of the peripheral nerve, appears unlimited for small and large molecule tracers, such as fluorescein (Abram et al., 2006), albumin (Olsson, 1971), horseradish peroxidase (Jacobs et al., 1976), and antibody IgG (Seitz et al., 1985). This has been attributed to a lack of tight junctions in the endothelium of microvessels in the DRG.

Despite these advances, a systematic and quantitative evaluation of the distribution of small-molecule drugs into peripheral nerves is still absent. In analogy to brain penetration, the extent of peripheral nerve penetration, as reflected by the peripheral nerve-to-blood unbound concentration ratio, is a most relevant parameter governing drug action (HammarlundUdenaes et al., 2008). The goal of this study was to examine the penetration of small-molecule drugs across a diverse range of physicochemical and transport properties into peripheral nerves (i.e., DRG and sciatic nerve) employing male SpragueDawley rats under constant-rate intravenous infusion condition. These results were then compared with the distribution into the CNS (i.e., brain and spinal cord penetration). Unbound fractions were also measured for a set of small molecules in rat blood, brains, spinal cords, DRG, and sciatic nerves. From these results, the tissue-to-blood unbound concentration ratios $\left(K_{\mathrm{p}, \mathrm{uu}}\right)$ for 11 small-molecule drugs were calculated for comparison between peripheral nerve and CNS tissues in rats. Imatinib is a substrate of both P-gp and BCRP (Kodaira et al., 2010; Liu et al., 2017). The influence of $N$-[4-[2-(6,7-dimethoxy-3,4dihydro-1 $H$-isoquinolin-2-yl)ethyl]phenyl]-5-methoxy-9-oxo$10 H$-acridine-4-carboxamide (GF120918), a P-gp and BCRP inhibitor (Matsson et al., 2009), on the penetration of imatinib into the peripheral nerve and CNS tissues in rats was also examined. Finally, we investigated the peripheral nerve and CNS tissue penetration of ProTx-II, a tarantula venom peptide with molecular mass of $3826 \mathrm{Da}$ in rats at steady state.

\section{Materials and Methods}

Materials. Amantadine, amitriptyline hydrochloride, atenolol, citalopram hydrobromide, clozapine, dantrolene sodium salt, fluphenazine dihydrochloride, granisetron hydrochloride, haloperidol, loxapine succinate salt, maprotiline hydrochloride, mesoridazine, nortriptyline hydrochloride, prazosin hydrochloride, ranitidine hydrochloride, and risperidone were obtained from Sigma-Aldrich (St. Louis, MO). Carbamazepine was purchased from Tokyo Chemical Industry (Tokyo, Japan). Loperamide hydrochloride was procured from Fluka (Buchs, Switzerland), minoxidil from the National Institute for the Control of Pharmaceutical and Biologic Products (Beijing, People's Republic of China), cyclosporine A from Wako (Osaka, Japan), and imatinib tosylate from Far Top Limited (Nanjing, Jiangsu, People's Republic of China). ProTx-II was purchased from Alomone Laboratories (Jerusalem, Israel). Ralfinamide and GF120918 were obtained from the GlaxoSmithKline compound library. All other reagents used were of bioanalytical grade or higher.

Animals. The male Sprague-Dawley rats were housed under standard environmental conditions (ambient temperature $21^{\circ} \mathrm{C}$, humidity $60 \%, 12$-hour light/dark cycle) with ad libitum access to food and water. All studies were conducted in accordance with the GSK Policy on the Care, Welfare and Treatment of Laboratory Animals and were reviewed the Institutional Animal Care and Use Committee either at GSK or by the ethical review process at the institution where the work was performed.

In Vivo Studies to Determine Peripheral Nerve and CNS Tissue Distribution for Small-Molecule Drugs in Rats. The brain-to-blood concentration ratio $\left(K_{\mathrm{p}, \mathrm{br}}\right)$, spinal cord-to-blood concentration ratio $\left(K_{\mathrm{p}, \mathrm{sc}}\right)$, DRG-to-blood concentration ratio $\left(K_{\mathrm{p}, \mathrm{drg}}\right)$, and sciatic nerve-to-blood concentration ratio $\left(K_{\mathrm{p}, \mathrm{sn}}\right)$ of small-molecule drugs were determined in male Sprague-Dawley rats. Rats were intravenously infused with carbamazepine (5.81 $\mu \mathrm{mol} / \mathrm{kg}$ per hour), haloperidol $(1.34 \mu \mathrm{mol} / \mathrm{kg}$ per hour $)$, ralfinamide $(3.87 \mu \mathrm{mol} / \mathrm{kg}$ per hour), ranitidine $(4.28 \mu \mathrm{mol} / \mathrm{kg}$ per hour), atenolol $(5.35 \mu \mathrm{mol} / \mathrm{kg}$ per hour), minoxidil (5.17 $\mu \mathrm{mol} / \mathrm{kg}$ per hour), dantrolene $(0.987 \mu \mathrm{mol} / \mathrm{kg}$ per hour), loperamide (1.59 $\mu \mathrm{mol} / \mathrm{kg}$ per hour), mesoridazine (1.72 $\mu \mathrm{mol} / \mathrm{kg}$ per hour $)$ imatinib $(1.42 \mu \mathrm{mol} / \mathrm{kg}$ per hour $)$, or cyclosporine A $(0.180 \mu \mathrm{mol} / \mathrm{kg}$ per hour $)$ for 6 hours at an infusion rate of $4 \mathrm{ml} / \mathrm{kg}$ per hour ( $2 \mathrm{ml} / \mathrm{kg}$ per hour used for imatinib). Four rats were used for each drug. The dose solutions were prepared in dimethylsulfoxide (DMSO): $10 \%$ hydroxypropyl- $\beta$-cyclodextrin (v/v, 1:99) for all small-molecule drugs except cyclosporine A, which was formulated in DMSO:15\% hydroxypropyl- $\beta$-cyclodextrin:polysorbate $20(\mathrm{v} / \mathrm{v} / \mathrm{v}, 1: 98: 1)$. Blood samples were collected in EDTA-pretreated tubes at 1, 2, 3, 4, 5, and 6 hours after dose administration. Tissues including brains, spinal cords, DRG, and sciatic nerves were harvested at a terminal time point ( 6 hours). The blood and tissue samples were stored at $-80^{\circ} \mathrm{C}$ before bioanalysis.

Influence of GF120918 on Peripheral Nerve and CNS Tissue Distribution of Imatinib. In a separate study, four rats received $22.2 \mu \mathrm{mol} / \mathrm{kg}$ GF120918 intraperitoneally $(5 \mathrm{ml} / \mathrm{kg}) 30$ minutes before a constant intravenous infusion of imatinib. The GF120918 was formulated in $1 \%$ methylcellulose as a suspension. The imatinib was solubilized in DMSO:10\% hydroxypropyl- $\beta$-cyclodextrin (v/v, 1:99) and intravenously infused into the rats at $1.42 \mu \mathrm{mol} / \mathrm{kg}$ per hour for 6 hours at an infusion rate of $2 \mathrm{ml} / \mathrm{kg}$ per hour. Blood and tissues including brains, spinal cords, DRG, and sciatic nerves were collected 6 hours after the imatinib dose and stored at $-80^{\circ} \mathrm{C}$ before bioanalysis.

In Vivo Study to Determine Peripheral Nerve and CNS Tissue Distribution for ProTx-II in Rats. ProTx-II was prepared in saline containing $0.1 \%$ polysorbate 20 and intravenously infused to four rats at $9.80 \mathrm{nmol} / \mathrm{kg}$ per hour for 24 hours at an infusion rate of $1 \mathrm{ml} / \mathrm{kg}$ per hour. Blood was sampled in EDTA-pretreated tubes at 21, 22,23 , and 24 hours after dose administration. At a terminal time point ( 24 hours after the dose administration of ProTx-II), the brains, spinal cords, DRG, and sciatic nerves were collected. Plasma was harvested after centrifugation, and plasma and tissue samples were stored at $-80^{\circ} \mathrm{C}$ before bioanalysis.

Measurement of Unbound Fractions in Blood and Tissues for Small-Molecule Compounds. The unbound fractions of smallmolecule compounds in rat blood, brains, spinal cords, DRG, and 
sciatic nerves were determined using the Rapid Equilibrium Dialysis device (RED; Pierce Biotechnology, ThermoFisher Scientific, Waltham, MA). Phosphate-buffered saline (PBS; pH 7.4) containing $10 \mathrm{mM}$ phosphate buffer, $2.7 \mathrm{mM}$ potassium chloride, and $137 \mathrm{mM}$ sodium chloride was obtained from Sigma-Aldrich. Fresh male Sprague-Dawley rat blood, brains, and spinal cords were obtained on the day of experiment, whereas DRG and sciatic nerves were collected beforehand and stored in a freezer. Brain, spinal cord, DRG, and sciatic nerve tissues were homogenized with a shear homogenizer with two, two, six, and five volumes of PBS (w/v), respectively. Blood was diluted with the same volume of PBS before dialysis.

The drug was added to blood and tissue homogenate to achieve a final concentration of $2 \mu \mathrm{M}$. Spiked blood and tissue homogenates $(100-200 \mu \mathrm{l})$ were placed into the sample chamber (indicated by the red ring) and dialyzed against an appropriate volume (300-350 $\mu \mathrm{l})$ of PBS buffer according to the manufacturer's specification. The RED apparatus was sealed with a self-adhesive lid and incubated for 4 hours in a 130 -rpm shaking air bath maintained at $37^{\circ} \mathrm{C}$.

After 4 hours, aliquots (10-50 $\mu \mathrm{l})$ were removed from each side of the insert and dispensed into a 96 -well plate. An equal volume of blank matrix or PBS was added to the corresponding wells to generate analytically identical sample matrices (matrix matching, brain homogenate used as blank matrix for spinal cord, DRG, and sciatic nerve). These matrix-matched samples were processed by protein precipitation by adding $300 \mu \mathrm{l}$ of acetonitrile containing an appropriate internal standard. The samples were then vortexed and centrifuged, and the supernatant was stored at $-80^{\circ} \mathrm{C}$ before bioanalysis.

The unbound fractions in undiluted blood $\left(f_{\mathrm{u}, \mathrm{bl}}\right)$, brain $\left(f_{\mathrm{u}, \mathrm{br}}\right)$, spinal cord $\left(f_{\mathrm{u}, \mathrm{sc}}\right)$, DRG $\left(f_{\mathrm{u}, \mathrm{drg}}\right)$, and sciatic nerve $\left(f_{\mathrm{u}, \mathrm{sn}}\right)$ were calculated by the following equation:

$$
f_{\mathrm{u}}=\frac{\frac{1}{\mathrm{D}}}{\left(\frac{1}{f_{\mathrm{u}, \text { measured }}}-1\right)+\frac{1}{\mathrm{D}}}
$$

where $\mathrm{D}$ represents the fold dilution of blood $(\mathrm{D}=2)$, brain $(\mathrm{D}=3)$, spinal cord $(\mathrm{D}=3), \mathrm{DRG}(\mathrm{D}=7)$, and sciatic nerve $(\mathrm{D}=6)$, and $f_{\mathrm{u}}$, measured is the ratio of mass spectrometric response of test compound determined from the buffer and blood or tissue homogenate samples.

Analysis of In Vitro and In Vivo Samples for Small-Molecule Compounds. Quantification of small-molecule compounds in the in vitro and in vivo samples was performed by the Acquity ultraperformance liquid chromatography (UPLC) system (Waters, Milford, MA) coupled with an AB Sciex 4000 Q-Trap mass spectrometer (AB Sciex, Foster City, CA). The samples were processed by deproteination with the appropriate volumes of acetonitrile containing an appropriate internal standard.

Brain blank matrix was used to construct standard curves to quantify the drug concentrations in spinal cord, DRG, and sciatic nerve samples from animal studies. The chromatographic separation was achieved on a Waters Acquity UPLC BEH C $18,2.1 \times 50 \mathrm{~mm}, 1.7$ $\mu \mathrm{m}$, UPLC HSS T3 $1.8 \mu \mathrm{m}, 100 \mathrm{~mm}$, or UPLC BEH Protein C4, $2.1 \times$ $100 \mathrm{~mm}, 300 \AA$ pore size, $1.7 \mu \mathrm{m}$ analytical column at $40^{\circ} \mathrm{C}$, using a gradient of aqueous (solvent $\mathrm{A}: 1 \mathrm{mM}$ ammonia acetate in water) and organic (solvent B: CH3CN-CH3OH with or without $0.1 \%$ formic acid $[4: 1, \mathrm{v} / \mathrm{v}])$ mobile phase at a flow rate of $450-600 \mu \mathrm{l} / \mathrm{min}$. The run time for each compound was in the range of 2.0-4.0 minutes. The key chromatographic and mass spectrometric settings, optimized to yield the best sensitivity for each test compound, are detailed in Supplemental Table 1.

Quantification of ProTx-II in Rat Plasma and Tissue Samples. Quantification of ProTx-II in the in vivo samples was performed by the Waters Acquity UPLC system coupled with an API 5000 triple-quadruple mass spectrometer (AB Sciex). Rat tissue samples were homogenized with three volumes of PBS for the brain and spinal cord and 10 volumes of PBS for the DRG and sciatic nerve. Brain blank matrix was used to construct standard curves to quantify ProTx-II concentrations in the spinal cord, DRG, and sciatic nerve.
The plasma and homogenized tissue samples were processed by solid phase extraction (Oasis $\mu$-elution HLB). An aliquot of the reconstituted plasma $(10 \mu \mathrm{l})$ or tissue extract $(20 \mu \mathrm{l})$ was injected onto the column (Acquity UPLC BEH Protein C4, $2.1 \times 100 \mathrm{~mm}, 300 \AA$ pore size, $1.7 \mu \mathrm{m}$ ). A mobile phase consisting of water containing $0.5 \%$ acetic acid (A) and acetonitrile-methanol (1:1, v/v) containing 0.5\% acetic acid (B) was employed. A flow rate of $0.6 \mathrm{ml} / \mathrm{min}$ was used.

The elution gradient for plasma, brain, and DRG was 0-0.5 minutes held at $15 \% \mathrm{~B}$; 0.5-2.2 minutes ramped to $40 \% \mathrm{~B}$; $2.2-2.25$ minutes further ramped to $90 \% \mathrm{~B} ; 2.25-2.8$ minutes maintained at $90 \% \mathrm{~B}$; 2.8-2.85 minutes down to $10 \% \mathrm{~B} ; 2.85-3.3$ minutes held at $10 \% \mathrm{~B}$; $3.3-3.35$ minutes ramped to $90 \% \mathrm{~B} ; 3.35-3.8$ minutes maintained at $90 \%$ $\mathrm{B}$; 3.8-3.85 minutes returned to $15 \% \mathrm{~B}$; and $3.85-5$ minutes held at $15 \% \mathrm{~B}$.

The elution gradient for spinal cord and sciatic nerve was $0-0.2$ minutes held at $15 \% \mathrm{~B} ; 0.2-3.0$ minutes ramped to $35 \% \mathrm{~B}$; 3.0-3.05 minutes further ramped to $90 \% \mathrm{~B}$; 3.05-3.5 minutes maintained at $90 \%$; $3.5-3.55$ minutes down to $15 \% \mathrm{~B} ; 3.55-4.0$ minutes held at $15 \% \mathrm{~B} ; 4.0-4.05$ minutes ramped to $90 \% \mathrm{~B} ; 4.05-4.5$ minutes maintained at $90 \% \mathrm{~B}$; $4.5-4.55$ minutes returned to $15 \% \mathrm{~B}$; and 4.55-5.7 minutes held at $15 \% \mathrm{~B}$.

Tandem mass spectrometric analysis of ProTx-II was performed in positive electrospray ionization mode by monitoring the ion transition (638.8-188.1) using an optimized cone voltage and collision energy. The low limit of quantification for ProTx-II was $0.78 \mathrm{nM}$ for plasma and $6.3 \mathrm{nM}$ for rat tissues. The assay relative accuracy was between $80 \%$ and $120 \%$.

The $K_{\mathbf{p}}$ and $K_{\mathrm{p}, \mathrm{uu}}$ Value Calculation. The $K_{\mathrm{p}, \mathrm{br}}, K_{\mathrm{p}, \mathrm{sc}}, K_{\mathrm{p}, \mathrm{drg}}$, and $K_{\mathrm{p}, \mathrm{sn}}$ values for each rat were calculated by the following equation:

$$
K_{\mathrm{p}}=\frac{C_{\text {tissue }}}{C_{\text {blood or plasma }}}
$$

where $C_{\text {tissue }}$ represents the measured drug concentration in brain, spinal cord, DRG, or sciatic nerve at a designated terminal time point ( 6 or 24 hours); $C_{\text {blood or plasma }}$ is the measured drug concentration in blood or plasma from the same rat.

The tissue-to-blood unbound concentration ratios in brain $\left(K_{\mathrm{p}, \mathrm{uu}, \mathrm{br}}\right)$, spinal cord $\left(K_{\mathrm{p}, \mathrm{uu}, \mathrm{sc}}\right)$, DRG $\left(K_{\mathrm{p} \text {,uu,drg }}\right)$, and sciatic nerve $\left(K_{\mathrm{p}, \mathrm{uu}, \mathrm{sn}}\right)$ for small-molecule drugs were determined by the following equation:

$$
K_{\mathrm{p}, \mathrm{uu}}=K_{\mathrm{p}} \times \frac{f_{\mathrm{u}, \mathrm{tissue}}}{f_{\mathrm{u}, \mathrm{bl}}}
$$

where $K_{p}$ represents the mean values the $K_{\mathrm{p}, \mathrm{br}}, K_{\mathrm{p}, \mathrm{sc}}, K_{\mathrm{p}, \mathrm{drg}}$, or $K_{\mathrm{p}, \mathrm{sn}}$ value at a designated terminal time point; $f_{\mathrm{u}, \text { tissue }}$ is the corresponding mean $f_{\mathrm{u}, \mathrm{br}}, f_{\mathrm{u}, \mathrm{sc}}, f_{\mathrm{u}, \mathrm{drg}}$, or $f_{\mathrm{u}, \mathrm{sn}}$; and $f_{\mathrm{u}, \mathrm{bl}}$ is the mean unbound fraction in blood.

The S.D. of the $K_{\mathrm{p} \text {,uu }}$ value (S.D. Kp,uu $_{\text {, }}$ ) was calculated according to the following law of propagation of error:

$$
\mathrm{S} . \mathrm{D} \cdot K_{\mathrm{p}, \mathrm{uu}}=K_{\mathrm{p}, \mathrm{uu}} \sqrt{\left(\frac{\mathrm{S} . \mathrm{D} \cdot K_{\mathrm{p}}}{K_{\mathrm{p}}}\right)^{2}+\left(\frac{\mathrm{S} . \mathrm{D} \cdot \mathrm{f}_{\mathrm{u}, \mathrm{tissue}}}{f_{\mathrm{u}, \mathrm{tissue}}}\right)^{2}+\left(\frac{\mathrm{S} \cdot \mathrm{D} \cdot \mathrm{f}_{\mathrm{u}, \mathrm{bl}}}{f_{\mathrm{u}, \mathrm{bl}}}\right)^{2}}
$$

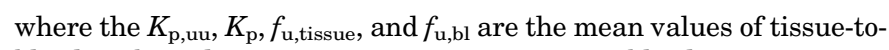
blood unbound concentration ratio, tissue-to-blood concentration ratio, unbound fraction in tissue homogenate, and blood unbound fraction, respectively; the S.D.Kp, S.D. $f u$,tissue, and S.D.fu,bl are the S.D. of $K_{\mathrm{p}}, f_{\mathrm{u} \text {,tissue }}$, and $f_{\mathrm{u}, \mathrm{bl}}$, respectively.

Statistical Analysis. All data are presented as mean \pm S.D. of technical or experimental replicates. Linear regression analysis was performed with Microsoft Excel 2007 (Microsoft, Redmond, WA). In all cases, $P<0.05$ was considered statistically significant.

\section{Results}

Drug Selection for Evaluation of Peripheral Nerve and CNS Tissue Distribution. Eleven small-molecule 
drugs with a wide range of physicochemical properties were selected for peripheral nerve and CNS tissue distribution studies in Sprague-Dawley rats. The physicochemical and transport properties of the selected drugs are summarized in Table 1. The small-molecule drugs show diverse physicochemical properties with cLogP ranging from -2.1 to 14.0 , molecular mass from 209 to $1202 \mathrm{Da}$, and topological polar surface area from 41 to $279 \AA^{2}$. The drug set covers a broad range of passive permeability spanning from 7.5 to $652 \mathrm{~nm} / \mathrm{s}$. Some of the drugs are recognized by two major efflux transporters: P-gp, BCRP, or both. A tarantula venom peptide ProTx-II with a high molecular mass (3826 Da) was also included in the study.

Unbound Fractions of Small-Molecule Compounds in Blood, Brain, Spinal Cord, DRG, and Sciatic Nerve. The unbound fractions for the 22 small-molecule compounds were determined using equilibrium dialysis with diluted rat blood $(2 \times)$, diluted rat brain $(3 \times)$, spinal cord $(3 \times)$, DRG $(7 \times)$, and sciatic nerve $(6 \times)$ tissue homogenates, and the results are shown in Table 2. Aside from those selected in peripheral nerve tissue penetration studies (11 compounds in Table 1), another 11 compounds were also included to expand the chemical space so that broader conclusions were allowed to be generated. The compound set is shown to cover a wide range of unbound fractions spanning five log units from $0.001 \%$ to $100 \%$.

We examined the concordance of the unbound fractions in rat brain with those in rat blood, spinal cord, sciatic nerve, and DRG. The results showed that the unbound fraction in brain $\left(f_{\text {u,br }}\right)$ for 22 small-molecule compounds was highly correlated with that in the spinal cord $\left(f_{\mathrm{u}, \mathrm{sc}}\right), \mathrm{DRG}\left(f_{\mathrm{u}, \mathrm{drg}}\right)$, and sciatic nerve $\left(f_{\mathrm{u}, \mathrm{sn}}\right)$ with the correlation coefficient $\left(\mathrm{R}^{2}\right)$ ranging from 0.97 to 0.99 (Fig. 1). This is likely due to the similarity of binding constituents in the CNS and peripheral nerve tissues.
This suggests that the $f_{\mathrm{u}, \mathrm{br}}$ value can serve as a surrogate for the $f_{\mathrm{u}, \mathrm{sc}}, f_{\mathrm{u}, \mathrm{drg}}$, and $f_{\mathrm{u}, \mathrm{sn}}$ value.

The amount of DRG ( $20 \mathrm{mg})$ and sciatic nerve $(\sim 80 \mathrm{mg})$ that can be excised from an adult rat is small as compared with brain ( 1.8 g) (Davies and Morris, 1993). Direct measurement of the $f_{\mathrm{u}, \mathrm{drg}}$ or $f_{\mathrm{u}, \mathrm{sn}}$ values for discovery compounds, which are required to determine the extent of peripheral nerve penetration, would result in the use of lots of animals. Use of the $f_{u, b r}$ value as a surrogate for the $f_{\mathrm{u}, \mathrm{sc}}, f_{\mathrm{u}, \mathrm{drg}}$, or $f_{\mathrm{u}, \mathrm{sn}}$ has the potential to reduce the animal usage in matrix collection for peripheral nerve tissue binding studies. A weaker correlation between $f_{\mathrm{u}, \mathrm{br}}$ and $f_{\mathrm{u}, \mathrm{bl}}\left(R^{2}=0.82\right)$ was observed than that between $f_{\mathrm{u}, \mathrm{br}}$ and $f_{\mathrm{u}, \mathrm{sc}}, f_{\mathrm{u}}$, $\mathrm{drg}$, or $f_{\mathrm{u}, \mathrm{sn}}$ (Fig. 1). This has been observed previously, and it is due to the very different binding constituents between brain tissue and blood (Summerfield et al., 2008; Di et al., 2011).

Distribution of Small-Molecule Drugs into Peripheral Nerves and CNS Tissues. Eleven compounds were dosed individually to rats $(n=4)$ for 6 hours by constant rate, continuous intravenous infusion. The concentrations in blood samples were determined during the infusion and reached a plateau at 6 hours for all compounds except carbamazepine and imatinib (Fig. 2). The concentrations of the test compounds in the brain, spinal cord, DRG, and sciatic nerve were determined at 6 hours and were used to calculate the $K_{\mathrm{p}, \mathrm{br}}$, $K_{\mathrm{p}, \mathrm{sc}}, K_{\mathrm{p}, \mathrm{sn}}$, and $K_{\mathrm{p} \text {,drg }}$ values (Table 3 ). With the availability of the $f_{\mathrm{u}}$ and $K_{\mathrm{p}}$ values, the $\mathrm{K}_{\mathrm{p} \text {,uu,br, }}, \mathrm{K}_{\mathrm{p} \text {,uu,sc }}, \mathrm{K}_{\mathrm{p} \text {,uu,sn }}$, and $K_{\mathrm{p} \text {,uu,drg }}$ values and S.D. for each drug can be calculated according to eq. 3 and eq. 4 , respectively, and are shown in Table 4. As reported in a previous study, the experimental variability of the $K_{\mathrm{p} \text {,uu }}$ values is notable, and the $K_{\mathrm{p} \text {,uu }}$ value of 0.2 (i.e., 5 -fold different than unity) should be used to distinguish compounds with significantly reduced tissue penetration (Dolgikh et al., 2016). Thereafter in this study,

TABLE 1

Physicochemical and transport properties of small-molecule drugs and the peptide ProTx-II employed in peripheral nerve and CNS tissue distribution studies

\begin{tabular}{|c|c|c|c|c|c|c|}
\hline \multirow{2}{*}{ Drugs } & $\underline{\text { Molecular Mass }}^{a}$ & $\underline{\operatorname{cLog} \mathrm{P}^{a}}$ & TPSA $^{a}$ & Passive Permeability & \multirow{2}{*}{ Permeability Classification ${ }^{b}$} & \multirow[t]{2}{*}{ P-gp and/or BCRP Substrate ${ }^{b}$} \\
\hline & Dalton & & $\AA^{2}$ & $\mathrm{~nm} / \mathrm{s}$ & & \\
\hline Carbamazepine & 236 & 2.4 & 46 & $652^{c}$ & High passive permeability, CNS drug ${ }^{c}$ & Not a P-gp substrate ${ }^{c}$ \\
\hline Haloperidol & 375 & 3.8 & 41 & $286^{c}$ & High passive permeability, CNS drug ${ }^{c}$ & Not a P-gp substrate ${ }^{c}$ \\
\hline Ralfinamide & 302 & 2.5 & 64 & $355^{d}$ & High passive permeability ${ }^{d}$ & Not a P-gp substrate ${ }^{d}$ \\
\hline Ranitidine & 314 & 0.67 & 86 & $7.5^{c}$ & Low passive permeability ${ }^{c}$ & Weak P-gp substrate ${ }^{c}$ \\
\hline Atenolol & 266 & -0.11 & 85 & $12^{c}$ & Moderate passive permeability ${ }^{c}$ & Not a P-gp substrate ${ }^{c}$ \\
\hline Minoxidil & 209 & -2.1 & 91 & $26^{c}$ & Moderate passive permeability $^{c}$ & Not a P-gp substrate ${ }^{c}$ \\
\hline Dantrolene & 314 & 1.6 & 124 & $453^{e}$ & High passive permeability $^{e}$ & BCRP specific substrate ${ }^{e}$ \\
\hline Loperamide & 477 & 4.7 & 44 & $456^{c}$ & High passive permeability $^{c}$ & P-gp substrate ${ }^{c}$ \\
\hline Mesoridazine & 386 & 4.6 & 24 & $149^{c}$ & High passive permeability, CNS drug ${ }^{c}$ & P-gp substrate ${ }^{c}$ \\
\hline Imatinib & 493 & 4.4 & 86 & $201^{e}$ & High passive permeability ${ }^{e}$ & P-gp and BCRP substrate \\
\hline Cyclosporine A & 1202 & 14 & 279 & $62.6^{f}$ & Moderate passive permeability ${ }^{f}$ & P-gp substrate ${ }^{g}$ \\
\hline ProTx-II & 3826 & $\mathrm{NC}$ & NC & NM & Likely very low for a peptide with high MM & $\mathrm{NM}$ \\
\hline
\end{tabular}

MM, molecular mass; NC, not calculated; NM, not measured; TPSA, topological polar surface area.

${ }^{a}$ The cLogP was calculated by BioByte version 4.3 (Biobyte, Claremont, CA); TPSA was calculated by the method developed by Ertl et al. (2000).

${ }^{b}$ Passive permeability is arbitrarily classified as follows: $<10 \mathrm{~nm} / \mathrm{s}$, low passive permeability; $10-100 \mathrm{~nm} / \mathrm{s}$, moderate passive permeability; $>100 \mathrm{~nm} / \mathrm{s}$, high passive

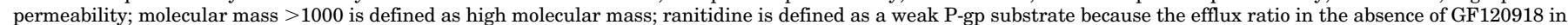
Madin-Darby canine kidney II (MDCKII)-MDR1 cells is 1.6, whereas other P-gp/BCRP substrates have reported efflux ratios greater than 2.

${ }^{c}$ Passive permeability was measured in MDCKII-MDR1 cells obtained from The Netherlands Cancer Institute in the presence of GF120918 (2 $\mu$ M) at pH 7.4 (Mahar Doan et al., 2002; Thiel-Demby et al., 2009) or obtained from the National Institutes of Health in the presence of GF120918 (2 $\mu$ M) at pH 7.4 (Summerfield et al., 2007).

${ }^{d}$ Artificial membrane permeability was reported herein (unpublished data). That the compound was not being recognized by P-gp was inferred from the $K_{\mathrm{p} \text {,uu,br }}$ value in rats.

${ }^{e}$ Passive permeability was measured in MDCKII-BCRP cells in the presence of $0.2 \mu \mathrm{M}$ of Ko143 [(3S,6S,12aS)-1,2,3,4,6,7,12,12a-octahydro-9-methoxy-6-(2-methylpropyl)-

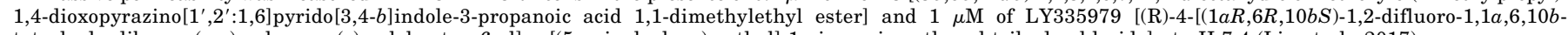
tetrahydrodibenzo-(a,e)cyclopropa(c)cycloheptan-6-yl]- $\alpha$-[(5-quinoloyloxy)methyl]-1-piperazine ethanol trihydrochloride] at pH 7.4 (Liu et al., 2017).

${ }^{f}$ Passive permeability was measured in Caco-2 cells obtained from the American Type Culture Collection (Manassas, VA) in the presence of $1 \mu \mathrm{M}$ GF120198 (von Richter et al., 2009).

${ }^{g}$ Cyclosporine A transported by P-gp was reported by Polli et al. (2001). 
TABLE 2

The percent unbound fractions of small-molecule drugs in blood, brain, spinal cord, sciatic nerve, and DRG

\begin{tabular}{lccccc}
\hline \multicolumn{1}{c}{ Drugs } & $f_{\mathrm{u}, \mathrm{bl}}(\%)^{a}$ & $f_{\mathrm{u}, \mathrm{br}}(\%)^{a}$ & $f_{\mathrm{u}, \mathrm{sc}}(\%)^{a}$ & $f_{\mathrm{u}, \mathrm{sn}}(\%)^{a}$ & $f_{\mathrm{u}, \mathrm{drg}}(\%)^{a}$ \\
\hline Carbamazepine & $26.6 \pm 1.7$ & $13.5 \pm 0.6$ & $13.8 \pm 0.6$ & $10.2 \pm 1.0$ & $15.8 \pm 1.9$ \\
Haloperidol & $9.71 \pm 1.26$ & $1.32 \pm 0.22$ & $0.89 \pm 0.33$ & $0.68 \pm 0.09$ & $1.19 \pm 0.28$ \\
Ralfinamide & $13.8 \pm 0.3$ & $2.36 \pm 0.17$ & $1.32 \pm 0.07$ & $2.25 \pm 0.30$ & $4.59 \pm 0.57$ \\
Ranitidine & $47.3 \pm 4.1$ & $85.3 \pm 52.5$ & $62.7 \pm 20.9$ & $20.5 \pm 6.2$ & $46.8 \pm 7.6$ \\
Atenolol & $41.5 \pm 1.3$ & $59.9 \pm 6.7$ & $71.3 \pm 12.2$ & $39.6 \pm 9.3$ & $42.9 \pm 13.5$ \\
Minoxidil & $64.0 \pm 7.0$ & $65.8 \pm 30.0$ & $50.1 \pm 5.9$ & $56.7 \pm 13.4$ & $100 \pm 0^{c}$ \\
Dantrolene & $3.08 \pm 0.58$ & $4.63 \pm 0.88$ & $3.32 \pm 0.31$ & $2.39 \pm 0.88$ & $7.74 \pm 2.79$ \\
Loperamide & $2.99 \pm 0.08$ & $0.58 \pm 0.01$ & $0.44 \pm 0.06$ & $0.22 \pm 0.02$ & $0.46 \pm 0.10$ \\
Mesoridazine & $9.66 \pm 0.74$ & $1.70 \pm 0.02$ & $1.62 \pm 0.32$ & $0.86 \pm 0.08$ & $1.66 \pm 0.33$ \\
Imatinib & $4.20 \pm 0.51$ & $2.15 \pm 0.14$ & $1.84 \pm 0.50$ & $1.18 \pm 0.10$ & $2.17 \pm 0.24$ \\
Cyclosporine A & $0.042 \pm 0.010$ & $0.011 \pm 0.000$ & $0.018 \pm 0.010$ & $0.031 \pm 0.036$ & $0.033 \pm 0.007$ \\
GF120918 & $0.015 \pm 0.002$ & $0.011 \pm 0.002$ & $0.0069 \pm 0.0004$ & $0.0064 \pm 0.0010$ & $0.0037 \pm 0.0002$ \\
Amantadine & $89.9 \pm 10.4$ & $16.0 \pm 1.8$ & $8.47 \pm 1.25$ & $10.6 \pm 0.9$ & $18.5 \pm 3.3$ \\
Amitriptyline & $5.90 \pm 0.56$ & $0.38 \pm 0.07$ & $0.28 \pm 0.03$ & $0.30 \pm 0.02$ & $0.51 \pm 0.04$ \\
Citalopram & $18.5 \pm 1.6$ & $2.06 \pm 0.09$ & $1.23 \pm 0.22$ & $1.98 \pm 0.11$ & $3.57 \pm 0.37$ \\
Clozapine & $6.04 \pm 0.25$ & $0.94 \pm 0.15$ & $0.46 \pm 0.06$ & $0.55 \pm 0.04$ & $0.97 \pm 0.22$ \\
Fluphenazine & $0.75 \pm 0.10$ & $0.069 \pm 0.006$ & $0.037 \pm 0.003$ & $0.036 \pm 0.002$ & $0.060 \pm 0.006$ \\
Granisetron & $42.3 \pm 6.1$ & $12.1 \pm 1.9$ & $9.85 \pm 1.20$ & $12.3 \pm 1.4$ & $17.1 \pm 1.6$ \\
Loxapine & $3.10 \pm 0.26$ & $0.36 \pm 0.04$ & $0.28 \pm 0.02$ & $0.19 \pm 0.01$ & $0.48 \pm 0.02$ \\
Maprotiline & $4.08 \pm 0.31$ & $0.23 \pm 0.09$ & $0.14 \pm 0.02$ & $0.14 \pm 0.01$ & $0.27 \pm 0.02$ \\
Nortriptyline & $4.12 \pm 0.28$ & $0.27 \pm 0.04$ & $0.15 \pm 0.01$ & $0.19 \pm 0.01$ & $0.35 \pm 0.01$ \\
Risperidone & $11.8 \pm 2.9$ & $7.61 \pm 0.40$ & $5.78 \pm 0.42$ & $6.97 \pm 0.69$ & $10.9 \pm 2.2$ \\
\hline
\end{tabular}

${ }^{a}$ Data were presented as mean \pm S.D. from three independent measurements unless otherwise indicated.

${ }^{b}$ Data were presented as mean \pm S.D. from six independent measurements.

${ }^{c}$ Concentrations in the receiver compartment were similar to or exceeded slightly those in the donor compartment. Thus, the unbound fraction in DRG was taken as $100 \%$.

a 5-fold difference from unity is considered to be significant in reduced or enhanced tissue penetration.

For drugs with high passive permeability that are not transported by P-gp, such as carbamazepine, haloperidol, and ralfinamide, no significant difference in peripheral nerve $\left(K_{\mathrm{p}, \mathrm{uu}, \mathrm{drg}}\right.$ and $\left.K_{\mathrm{p}, \mathrm{uu}, \mathrm{sn}}\right)$ and CNS $\left(K_{\mathrm{p}, \mathrm{uu}, \mathrm{br}}\right.$ and $\left.K_{\mathrm{p}, \mathrm{uu}, \mathrm{sc}}\right)$ tissue penetration was observed (Table 4 ). In line with their passive diffusion transport mechanism, the $K_{\mathrm{p}, \mathrm{uu}}$ values of the three
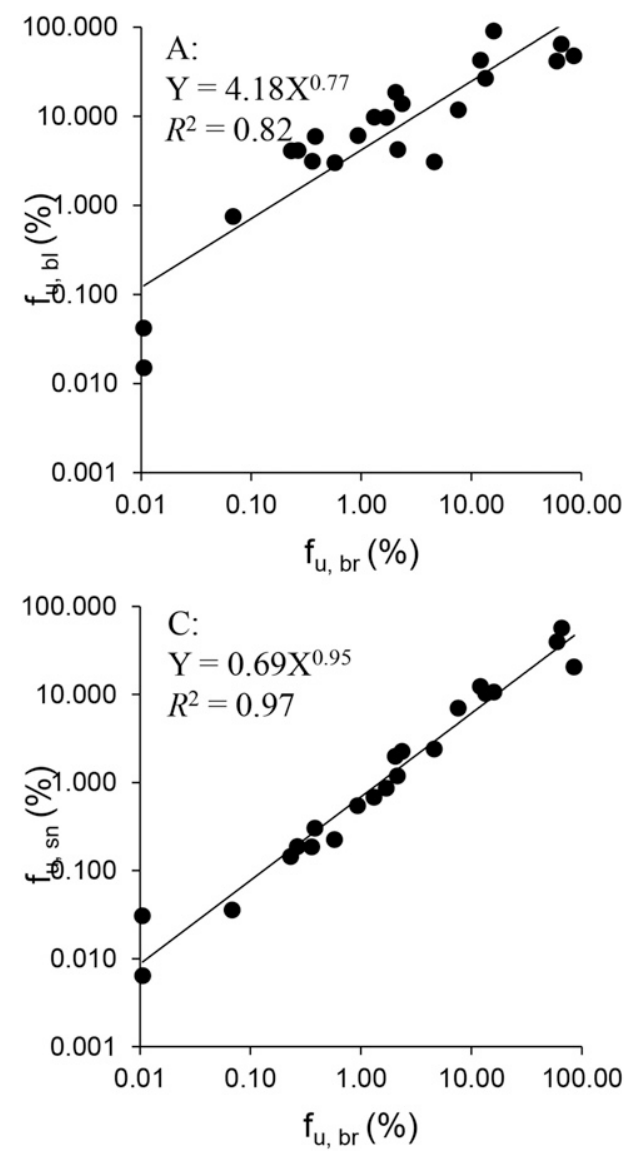
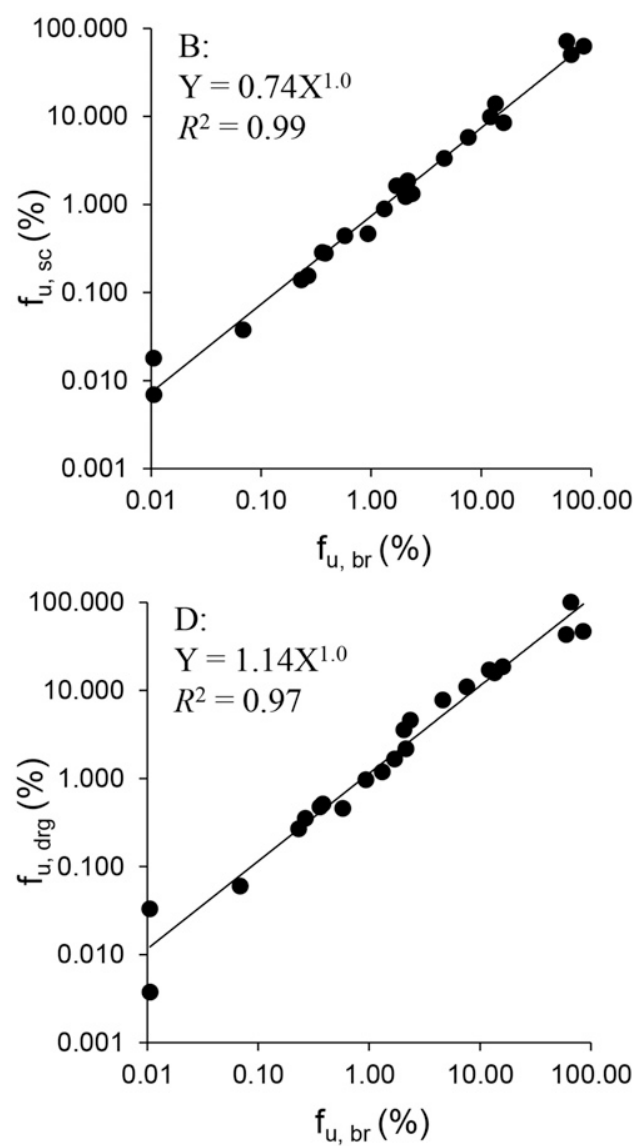

Fig. 1. Correlation between $f_{\mathrm{u}, \mathrm{br}}$ and $f_{\mathrm{u}, \mathrm{bl}}$ $(\mathrm{A}), f_{\mathrm{u}, \mathrm{sc}}(\mathrm{B}), f_{\mathrm{u}, \mathrm{sn}}(\mathrm{C})$, and $f_{\mathrm{u}, \mathrm{drg}}(\mathrm{D})$ for 22 small-molecule compounds. 


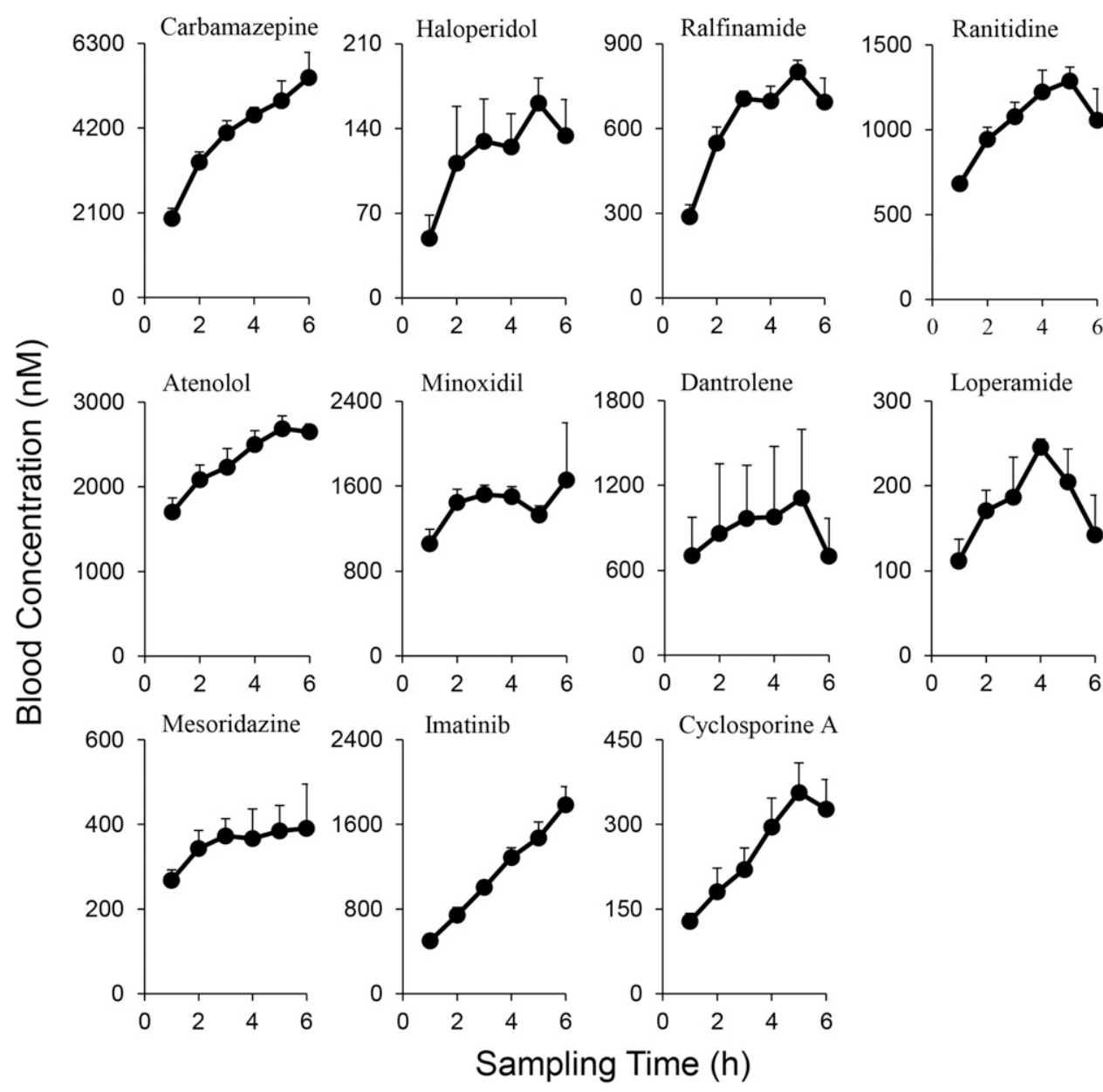

Fig. 2. The blood concentration-time profiles of 11 small-molecule drugs in rats receiving a constant intravenous infusion for 6 hours. Four rats were used for each drug. The dose for each drug is described in Materials and Methods.

drugs across different tissues were generally within 5-fold of unity. The $K_{\mathrm{p} \text {,uu }}$ values of haloperidol were generally higher than unity (2.34-6.42), likely due to experimental variability.

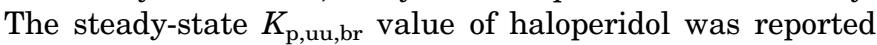
previously to be 1.77 in rats (Summerfield et al., 2016).

For drugs with low to moderate passive permeability that are not or are only weakly recognized by P-gp, such as ranitidine, atenolol, and minoxidil, the rank order in the tissue $K_{\mathrm{p} \text {,uu }}$ values was DRG $>$ sciatic nerve $>$ spinal cord $>$ brain (Fig. 3; Table 4). This indicated higher peripheral nerve tissue penetration as compared with CNS penetration for this class of drugs. In addition, the $K_{\mathrm{p}, \mathrm{uu}, \mathrm{drg}}$ values of ranitidine, atenolol, and minoxidil ranged from 1.41 to 1.54 , and the $K_{\mathrm{p}, \mathrm{uu} \text {,sn }}$ values spanned from 0.308 to 0.807 , which did not significantly deviate from unity, indicating no or limited diffusion barrier in peripheral nerve tissues (Table 4 ). In contrast, the $K_{\mathrm{p} \text {,uu,sc }}$ and $K_{\mathrm{p} \text {,uu,br }}$ values of ranitidine, atenolol, and minoxidil were below 0.228 , which suggested permeability-limited restriction in CNS penetration.

For drugs with high passive permeability that interacted with P-gp, BCRP, or both, including dantrolene, loperamide, mesoridazine, and imatinib, the rank order in the tissue $K_{\mathrm{p} \text {,uu }}$

TABLE 3

The blood and tissue concentrations and tissue-to-blood concentration ratios of small-molecule drugs in brain, spinal cord, sciatic nerve, and DRG at 6 hours in rats receiving constant intravenous infusion

\begin{tabular}{|c|c|c|c|c|c|c|c|c|c|}
\hline Drugs $^{a}$ & $C_{\mathrm{bl}}(\mathrm{nM})$ & $C_{\mathrm{br}}(\mathrm{nM})$ & $K_{\mathrm{p}, \mathrm{br}}$ & $C_{\mathrm{sc}}(\mathrm{nM})$ & $K_{\mathrm{p}, \mathrm{sc}}$ & $C_{\mathrm{sn}}(\mathrm{nM})$ & $K_{\mathrm{p}, \mathrm{sn}}$ & $C_{\mathrm{drg}}(\mathrm{nM})$ & $K_{\mathrm{p}, \mathrm{drg}}$ \\
\hline Carbamazepine & $5455 \pm 625$ & $6785 \pm 904$ & $1.25 \pm 0.21$ & $9818 \pm 961$ & $1.82 \pm 0.31$ & $9098 \pm 1540$ & $1.70 \pm 0.44$ & $11,190 \pm 1137$ & $72.05 \pm 0.06$ \\
\hline Haloperidol & $134 \pm 30$ & $4423 \pm 259$ & $34.5 \pm 9.1$ & $4400 \pm 415$ & $34.0 \pm 7.0$ & $4235 \pm 548$ & $33.5 \pm 11.5$ & $6560 \pm 1133$ & $352.5 \pm 21.7$ \\
\hline Ralfinamide & $694 \pm 85$ & $6665 \pm 1021$ & $9.79 \pm 2.23$ & $6260 \pm 398$ & $9.09 \pm 0.85$ & $9305 \pm 440$ & $13.6 \pm 2.3$ & $10,360 \pm 2402$ & $215.0 \pm 3.1$ \\
\hline Ranitidine & $1056 \pm 186$ & $<30.0$ & $<0.029$ & $49.1 \pm 8.4$ & $0.047 \pm 0.010$ & $749 \pm 149$ & $0.710 \pm 0.076$ & $1513 \pm 73$ & $1.46 \pm 0.22$ \\
\hline Atenolol & $2647 \pm 92$ & $62.0 \pm 12.2$ & $0.023 \pm 0.005$ & $171 \pm 36$ & $0.064 \pm 0.013$ & $1855 \pm 225$ & $0.701 \pm 0.087$ & $3613 \pm 224$ & $1.37 \pm 0.12$ \\
\hline Minoxidil & $1658 \pm 541$ & $266 \pm 19$ & $0.170 \pm 0.040$ & $439 \pm 93$ & $0.291 \pm 0.121$ & $1473 \pm 91$ & $0.911 \pm 0.285$ & $1573 \pm 279$ & $0.987 \pm 0.185$ \\
\hline Dantrolene & $697 \pm 269$ & $62.6 \pm 11.7$ & $0.077 \pm 0.006$ & $118 \pm 1$ & $0.148 \pm 0.026$ & $341 \pm 137$ & $0.493 \pm 0.081$ & $403 \pm 159$ & $0.575 \pm 0.093$ \\
\hline Loperamide & $142 \pm 47$ & $43.0 \pm 9.5$ & $0.327 \pm 0.147$ & $154 \pm 115$ & $1.16 \pm 0.95$ & $1022 \pm 157$ & $7.63 \pm 2.26$ & $1278 \pm 312$ & $9.20 \pm 1.29$ \\
\hline Mesoridazine & $391 \pm 104$ & $224 \pm 11$ & $0.598 \pm 0.126$ & $326 \pm 30$ & $0.873 \pm 0.199$ & $954 \pm 78$ & $2.59 \pm 0.80$ & $1353 \pm 113$ & $3.59 \pm 0.69$ \\
\hline Imatinib & $1785 \pm 171$ & $112 \pm 4$ & $0.063 \pm 0.006$ & $172 \pm 30$ & $0.096 \pm 0.009$ & $1580 \pm 113$ & $0.891 \pm 0.099$ & $2475 \pm 287$ & $1.39 \pm 0.08$ \\
\hline Cyclosporine A & $327 \pm 53$ & $<6.46$ & $<0.020$ & $<4.80$ & $<0.015$ & $97.4 \pm 24.0$ & $0.299 \pm 0.066$ & $62.8 \pm 9.0$ & $0.194 \pm 0.033$ \\
\hline
\end{tabular}

${ }^{a}$ The dose for each drug is described in Materials and Methods. Four rats were used for each drug. 
TABLE 4

The tissue-to-blood unbound concentration ratio of small-molecule drugs in brain, spinal cord, sciatic nerve, and DRG

\begin{tabular}{lcccc}
\hline \multicolumn{1}{c}{ Drugs } & $K_{\mathrm{p}, \text { uu,br }}$ & $K_{\mathrm{p}, \mathrm{uu}, \mathrm{sc}}$ & $K_{\mathrm{p}, \mathrm{uu} \text {, sn }}$ & $K_{\mathrm{p}, \mathrm{uu}, \mathrm{drg}}$ \\
\hline Carbamazepine & $0.636 \pm 0.117$ & $0.948 \pm 0.176$ & $0.655 \pm 0.186$ & $1.22 \pm 0.17$ \\
Haloperidol & $4.68 \pm 1.59$ & $3.10 \pm 1.39$ & $2.34 \pm 0.91$ & $6.42 \pm 3.18$ \\
Ralfinamide & $1.67 \pm 0.40$ & $0.871 \pm 0.097$ & $2.21 \pm 0.48$ & $4.97 \pm 1.21$ \\
Ranitidine & $<0.05$ & $0.063 \pm 0.025$ & $0.308 \pm 0.102$ & $1.44 \pm 0.35$ \\
Atenolol & $0.034 \pm 0.008$ & $0.111 \pm 0.030$ & $0.670 \pm 0.179$ & $1.41 \pm 0.46$ \\
Minoxidil & $0.175 \pm 0.092$ & $0.228 \pm 0.102$ & $0.807 \pm 0.328$ & $1.54 \pm 0.33$ \\
Dantrolene & $0.115 \pm 0.032$ & $0.160 \pm 0.044$ & $0.383 \pm 0.170$ & $1.45 \pm 0.63$ \\
Loperamide & $0.063 \pm 0.029$ & $0.170 \pm 0.142$ & $0.573 \pm 0.176$ & $1.40 \pm 0.37$ \\
Mesoridazine & $0.105 \pm 0.024$ & $0.146 \pm 0.046$ & $0.230 \pm 0.076$ & $0.617 \pm 0.176$ \\
Imatinib & $0.032 \pm 0.006$ & $0.042 \pm 0.013$ & $0.251 \pm 0.046$ & $0.715 \pm 0.125$ \\
Cyclosporine A & $<0.005$ & $<0.006$ & $0.218 \pm 0.267$ & $0.154 \pm 0.057$ \\
\hline
\end{tabular}

values was DRG $>$ sciatic nerve $>$ spinal cord $>$ brain (Fig. 3 ; Table 4), suggesting higher peripheral nerve than CNS tissue penetration for these efflux transporter substrates. The $K_{\mathrm{p}, \mathrm{uu}, \mathrm{drg}}$ values of dantrolene, loperamide, mesoridazine, and imatinib ranged from 0.617 to 1.45 , which were slightly higher than the $K_{\mathrm{p}, \mathrm{uu}, \mathrm{sn}}$ values $(0.230-0.570)$, implying no or limited diffusion barrier in peripheral nerve tissues. Consistent with their transport mechanisms across the blood-brain barrier (BBB) and blood-spinal cord barrier (BSCB), the $K_{\mathrm{p}, \mathrm{uu}, \mathrm{br}}$ and $K_{\mathrm{p}, \mathrm{uu}, \mathrm{sc}}$ values of dantrolene, loperamide, mesoridazine, and imatinib were significantly lower than unity (0.032-0.170), indicating efflux transporter-mediated restriction in CNS penetration.
For cyclosporine A which has moderate passive permeability and interacts with P-gp, the $K_{\mathrm{p}, \mathrm{uu}, \mathrm{drg}}$ and $K_{\mathrm{p} \text {,uu,sn }}$ values were 0.154 and 0.218 , respectively, indicating limited diffusion barrier in peripheral nerve tissues. In alignment with its CNS transport mechanism, the $K_{\mathrm{p}, \mathrm{uu}, \mathrm{br}}$ and $K_{\mathrm{p}, \mathrm{uu}, \mathrm{sc}}$ values were below 0.006 .

Influence of GF120918 on Distribution of Imatinib into Peripheral Nerves and CNS Tissues. GF120918 was dosed intraperitoneally to rats at $22.2 \mu \mathrm{mol} / \mathrm{kg} 30$ minutes before intravenous infusion of imatinib. The rat blood concentration-time profile of imatinib in the presence of GF120918 was similar to that in the absence of GF120918 (Fig. 4A). The rat blood and tissue concentrations of GF120918

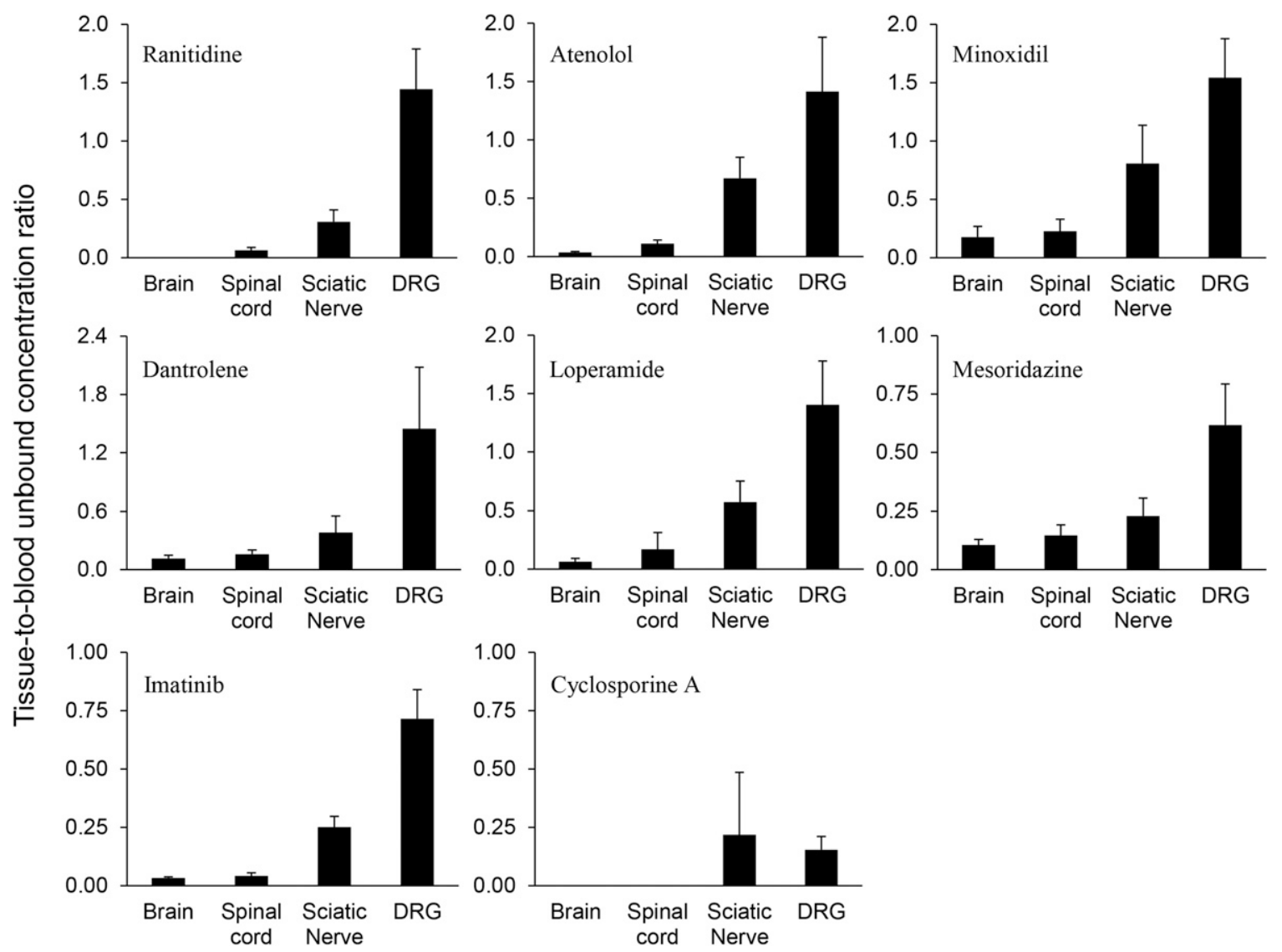

Fig. 3. The tissue-to-blood unbound concentration ratios for small-molecule drugs with low-to-moderate passive permeability that are not or are only weakly transported by P-gp (ranitidine, atenolol, minoxidil); with high passive permeability that interact with P-gp (loperamide, mesoridazine), BCRP (dantrolene), or both (imatinib); and with moderate permeability and that are recognized by P-gp (cyclosporine A). 

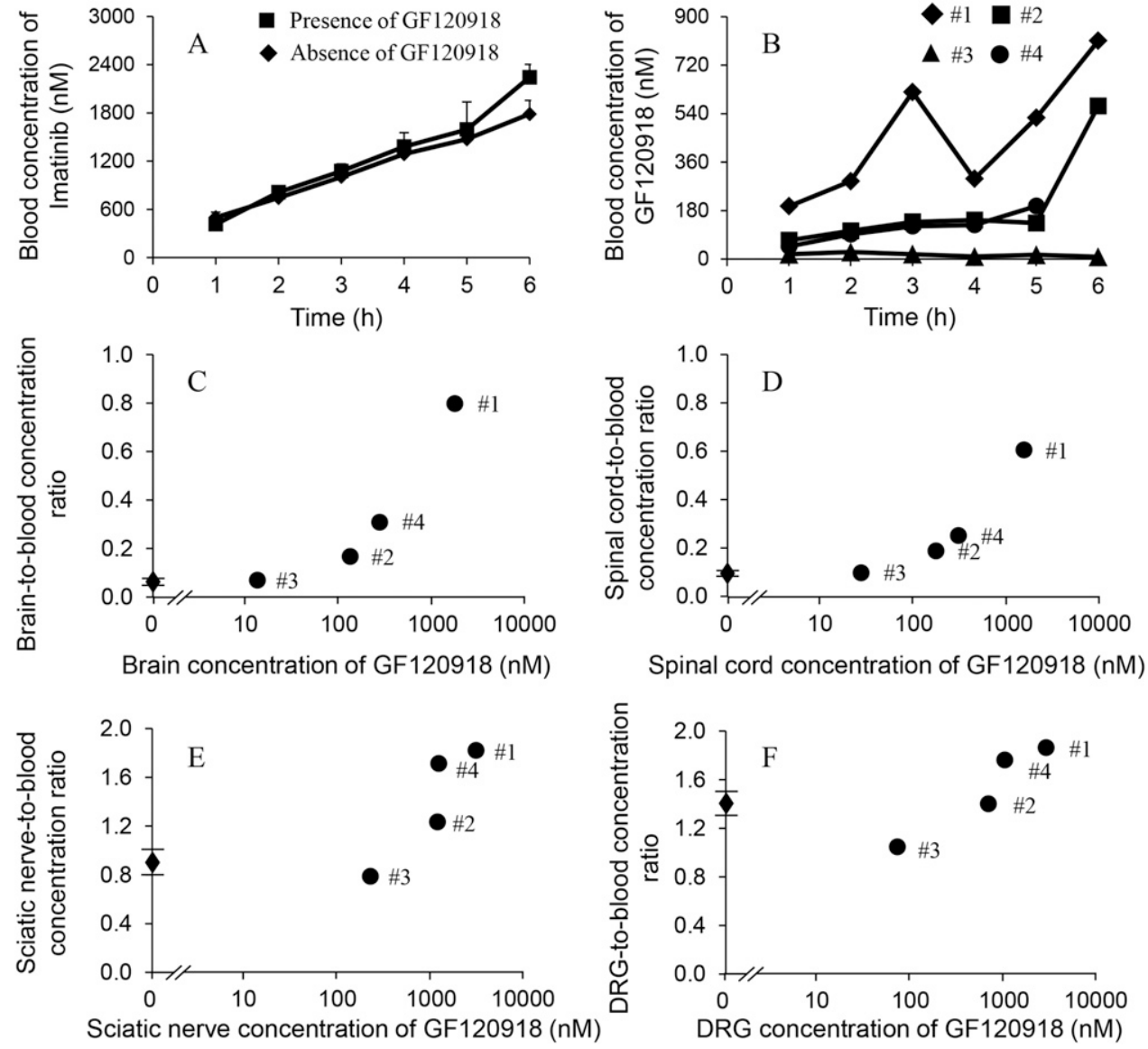

Fig. 4. Influence of GF 120918 on the peripheral nerve and CNS tissue distribution of imatinib. (A) Blood concentration-time profiles of imatinib in rats $(n=4)$ receiving a constant intravenous infusion for 6 hours in the absence $(\bullet)$ or

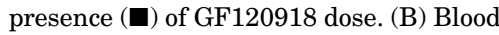
concentration-time profiles of GF120918 in rats receiving $22.2 \mu \mathrm{mol} / \mathrm{kg}$ GF120918 intraperitoneally 30 minutes before imatinib dose. The time shown on the $x$ axis was started from the administration of imatinib. (C-F) Brain-, spinal cord-, sciatic nerve-, and DRG-to-blood concentration ratio of imatinib at 6 hours in rats receiving a constant intravenous infusion of imatinib in the absence $(\downarrow)$ or presence (๑) of GF120918 dose. Numbers (1-4) in (B-F) represent an induvial rat receiving a constant intravenous infusion of imatinib in the presence of GF120918 dose. were variable after intraperitoneal administration at $22.2 \mu \mathrm{mol} / \mathrm{kg}$ (Fig. 4, B-F). This allowed us to explore the GF120918 concentration-dependent increase in peripheral nerve and CNS tissue penetration of imatinib (Fig. 4, C-F).

The highest blood and tissue concentrations of GF120918 were observed in Rat \#1, which corresponded to largest increase in the $K_{\mathrm{p}, \mathrm{br}}\left(12.6\right.$-fold) and $K_{\mathrm{p}, \mathrm{sc}}(6.3$-fold) values as compared with rats in the absence of GF120918. The extent of the $K_{\mathrm{p}, \mathrm{br}}$ increase for imatinib was comparable to those observed in $\mathrm{Mdr} 1 \mathrm{a} / 1 \mathrm{~b}^{(-/-)} / \mathrm{Bcrp}^{(-/-)}$mice (12.6- to 63.6-fold) but higher than those in $\mathrm{Mdr} 1 \mathrm{a} / 1 \mathrm{~b}^{(-/-)}$(1.0- to 4.46 -fold) and $\mathrm{Bcrp}^{(-/-)}$(0.86- to 1.0-fold) mice relative to wild-type mice (Kodaira et al., 2010), suggesting that the blood and tissue concentrations of GF120918 achieved in Rat \#1 were sufficient to modulate P-gp and BCRP activities. Under these circumstances, the $K_{\mathrm{p}, \mathrm{sn}}$ value of imatinib was only slightly enhanced by 2 -fold, and the $K_{\mathrm{p} \text {,drg }}$ value was unchanged in Rat \#1. No change in the $K_{\mathrm{p}, \mathrm{br}}, K_{\mathrm{p} \text {,sc }}$, $K_{\mathrm{p}, \mathrm{sn}}$, and $K_{\mathrm{p}, \mathrm{drg}}$ values of imatinib (0.75- to 1.1-fold) was observed in Rat \#3, which was consistent with the lowest blood and tissue concentrations of GF120918. These results imply that, in contrast to their restrictive role in CNS penetration, P-gp and BCRP have a limited impact on drug distribution of small-molecule drugs into peripheral nerve tissues.

Distribution of ProTx-II into Peripheral Nerves and CNS Tissues. Rats were dosed with the peptide ProTx-II by constant intravenous infusion at $37.5 \mu \mathrm{g} / \mathrm{h}$ per kilogram for 24 hours, and the plasma concentration of ProTx-II reached a steady state (Fig. 5A). The DRG-to-plasma concentration ratio of ProTx-II was $10.5 \pm 1.0$ at steady state, whereas sciatic nerve-, spinal cord-, and brain-to-plasma concentration ratios were below 0.23 (Fig. 5B). These results indicate that DRG is permeable to ProTx-II whereas the distribution of ProTx-II into sciatic nerves is restricted.

\section{Discussion}

In tissues with protective barriers such as the $\mathrm{BBB}$ and $\mathrm{BNB}$, the systemic unbound concentration may not be a reliable surrogate for the tissue unbound concentration of drugs. The equilibration between a compound's tissue and systemic unbound concentrations is described by the $K_{\mathrm{p} \text {,uu }}$ value, which can be either below or above unity. The transport mechanisms of compounds across tissue barriers can be inferred from the $K_{\mathrm{p} \text {,uu }}$ values at steady state. The compounds' $K_{\text {p,uu }}$ values below 1 suggest carrier-mediated efflux and/or low passive permeability and above 1 indicate active influx, whereas the $K_{\mathrm{p} \text {,uu }}$ values equal to unity represent passive permeability and/or balanced active efflux/influx processes (Hammarlund-Udenaes et al., 2008; Rankovic, 2015; Summerfield et al., 2016). As compared with BBB penetration, the physicochemical and transport properties governing the drug distribution into peripheral nerves remain largely unexplored. In this study, we systematically evaluated the peripheral nerve penetration for drugs with diverse physicochemical and transport properties administered to rats under constant intravenous infusion and compared this with their CNS penetration. The results offer insights not only into the characteristics of drugs but also into the relevance of $\mathrm{P}$-gp and 


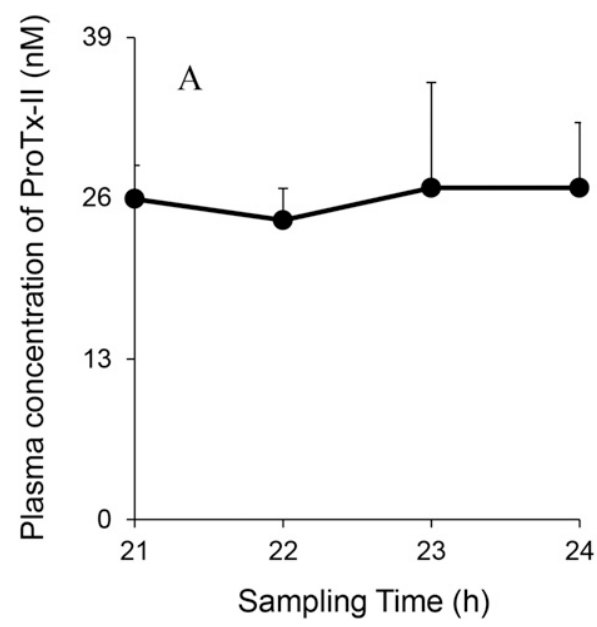

BCRP transport with regard to drug distribution into peripheral nerves such as the DRG and sciatic nerve.

The DRG contains the cell bodies of sensory neurons and is located between the dorsal root and the peripheral nerve. The DRG has been proposed as an important therapeutic target for neurologic diseases such as neuropathic pain (Sapunar et al., 2012; Liem et al., 2016). There appears to be no diffusion barrier at the DRG for drugs with very different physicochemical and transport properties, as indicated by the $K_{\mathrm{p} \text {,uu,drg }}$ values greater than 0.5 for all small molecules investigated except cyclosporine A. Cyclosporine A has an extremely low unbound fraction in blood and peripheral nerve tissues $(0.01 \%-0.04 \%)$. Therefore, caution should be exercised as to the calculated $K_{\mathrm{p}, \mathrm{uu} \text {,drg }}$ value because an inherent challenge exists for accurate determination of unbound fractions for highly bound compounds (Riccardi et al., 2015). The efflux transporters P-gp and BCRP do not have any impact on the DRG penetration for their substrates. This conclusion is supported by two facts: 1 ) the $K_{\mathrm{p}, \mathrm{uu} \text {,drg }}$ values of P-gp and/or BCRP substrates are all above 0.5 except cyclosporine A, and 2) GF120918 does not have any appreciable influence on the DRG penetration of imatinib. The leakiness of the DRG is corroborated by the high $K_{\mathrm{p}, \mathrm{drg}}$ value for ProTx-II, a peptide with high molecular mass. This can be explained by the DRG possessing microvessels with fenestrated endothelia and a permeable connective tissue capsule (Arvidson, 1979; Abram et al., 2006). These results demonstrate that small-molecule drugs can be easily delivered to the DRG without any appreciable diffusion barrier.

In fiber-rich nerve trunks such as sciatic nerve, the BNB is present to maintain the homeostasis of endoneurial milieu. In the present study, we found that the sciatic nerve is permeable to small-molecule drugs with large structural diversity, as indicated by the $K_{\mathrm{p} \text {,uu,sn }}$ values greater than 0.2 for all small-molecule drugs investigated. In analogy to the kinetics of $\mathrm{BBB}$ penetration, low tissue permeability will negatively affect the $K_{\mathrm{p} \text {,uu }}$ value and require longer time to achieve equilibrium (Liu et al., 2008). Passive permeability as low as $\sim 10 \mathrm{~nm} / \mathrm{s}$ does not significantly decrease BNB penetration but clearly breaches CNS penetration, as demonstrated by the difference in $K_{\mathrm{p} \text {,uu,sn }}$ and $K_{\mathrm{p} \text {,uu,br }}$ values for ranitidine and atenolol. The lower permeability cutoff required for BNB penetration likely reflects lower endoneurial fluid turnover and more permeable endoneurial microvasculature as compared with brain and spinal cord (Rechthand et al., 1988; Weerasuriya and Mizisin, 2011).
Limited BNB penetration was observed for ProTx-II, which is expected to have a much lower permeability based on its physicochemical properties. Other than this, we have not further investigated whether substances with permeability far lower than $10 \mathrm{~nm} / \mathrm{s}$ (e.g., solutes, ions, antibodies) would have impaired $\mathrm{BNB}$ penetration. In theory, this is very likely if the permeability clearance of substances across the BNB is approaching or even below the sciatic nerve endoneurial fluid bulk flow in a situation analogous to the BBB penetration kinetics of hydrophilic compounds (Liu et al., 2008). Supportive evidence comes from the reported diffusion restriction across the BNB for very hydrophilic small molecules (e.g., sucrose) and macromolecules (Rechthand et al., 1987; Poduslo et al., 1994), which are all expected to have very low permeability.

Specialized transport systems are expected to be expressed on the restrictive $\mathrm{BNB}$ to facilitate directional substance exchange between the endoneurial space and systemic circulation. In fact, expression of a number of nutrient and xenobiotic transporters on primary and immortalized human endoneurial endothelial cells has been demonstrated (Yosef et al., 2010; Abe et al., 2012; Yosef and Ubogu, 2013). The functional role of $\mathrm{P}$-gp or BCRP in affecting drug distribution into the peripheral nerve was particularly investigated. Slightly higher accumulation of the P-gp substrate drugs vinblastine (2.3- to 4.4-fold) and doxorubicin (1.5-fold) but not cisplatin (0.87- to 1.1 -fold) was observed in the sciatic nerve in $M d r 1 a^{(-1-)}$ mice as compared with wild-type mice (Saito et al., 2001). The impact of P-gp and BCRP on the distribution of their substrates into the sciatic nerve was not demonstrated in rats (Huang et al., 2015). In concordance with these observations, we conclude that P-gp and BCRP have a limited impact on BNB penetration. This conclusion is supported by two lines of evidence: 1 ) the $K_{\mathrm{p} \text {,uu,sn }}$ values for efflux transporter substrates are in the range of $0.22-0.57$, and 2) GF120918 can only enhance the $K_{\text {p,uu,sn }}$ value of imatinib by 2 -fold at a concentration that can drastically increase the $K_{\mathrm{p} \text {,uu,br }}$ and $K_{\mathrm{p} \text {,uu,sc }}$ of imatinib.

High passive permeability and low P-gp efflux potential are known to be required for good CNS penetrants (Mahar Doan et al., 2002; Di et al., 2013). The $K_{\mathrm{p} \text {,uu,br }}$ and $K_{\mathrm{p} \text {,uu,sc }}$ values for drugs with low-to-moderate passive permeability or P-gp/BCRP substrates were much lower than the $K_{\mathrm{p} \text {,uu,sn }}$ and $K_{\mathrm{p} \text {,uu,drg }}$ values, clearly indicating a more restrictive nature of the BBB and BSCB. The $K_{\mathrm{p} \text {,uu,sc }}$ values are similar to the $K_{\mathrm{p} \text {,uu,br values (within } 3 \text {-fold) }}$ 
for the majority of compounds investigated. Despite this, there is a trend that the $K_{\mathrm{p}, \mathrm{uu} \text {,sc }}$ values are slightly greater than those of the $K_{\mathrm{p}, \mathrm{uu} \text {,br }}$ values for low-to-moderate permeable compounds or P-gp/BCRP substrates, likely due to increased permeability and reduced expression of efflux transporters in the BSCB as compared with the BBB (Bartanusz et al., 2011).

Breakdown of the BNB has been reported in many disorders of the peripheral nervous system including Guillain-Barré syndrome, chronic inflammatory demyelinating polyneuropathy, and diabetic neuropathy. Morphologic abnormalities of endothelial cells constituting the BNB in these neuropathies include fenestration of endoneurial microvessels, gaps between adjacent endothelial cells, and the disappearance of tight junctions (Kanda, 2013). The impact of BNB dysfunction in diseases on drug distribution into the peripheral nerve remains to be explored. Despite this, based on the knowledge obtained from this study, we could reasonably believe that BNB breakdown will only have a limited impact on peripheral nerve penetration of small-molecule therapeutics, but it is likely to have a more profound influence on peripheral nerve penetration of very hydrophilic small molecules, ions, and biologics when active transport mechanisms are minimal or lacking for these substances with very low membrane permeability.

In conclusion, we have shown that the peripheral nerve is permeable to the small-molecule drugs we have investigated and that P-gp and BCRP have a limited impact on drug penetration into peripheral nerves. For biologics as large as ProTx-II, penetration into the DRG was demonstrated, but its distribution into sciatic nerve and CNS tissues is restricted. To our knowledge, this is the first study to systematically and quantitatively evaluate the peripheral nerve penetration of small-molecule drugs with diverse physicochemical and transport properties. These findings further our understanding of the molecular mechanisms governing BNB penetration, which should help in identifying compounds to treat diseases with targets located at the peripheral nerve.

\section{Authorship Contributions}

Participated in research design: H. Liu, Fu, Lu, Yu, Wan, Wang, Summerfield, Dong.

Conducted experiments: H. Liu, Chen, Huang, Sun, Wu, Zhu, Zhen, J. Liu, Cai, Yang.

Performed data analysis: $\mathrm{H}$. Liu, Sun, $\mathrm{Fu}, \mathrm{Lu}$.

Wrote or contributed to the writing of the manuscript: $\mathrm{H}$. Liu, Fu, $\mathrm{Lu}$, Zhang, Yu, Wan, Wang, Summerfield, Dong, Terstappen.

\section{References}

Abe M, Sano Y, Maeda T, Shimizu F, Kashiwamura Y, Haruki H, Saito K, Tasaki A, Kawai M, Terasaki T, et al. (2012) Establishment and characterization of human peripheral nerve microvascular endothelial cell lines: a new in vitro blood-nerve barrier (BNB) model. Cell Struct Funct 37:89-100.

Abram SE, Yi J, Fuchs A, and Hogan QH (2006) Permeability of injured and intact peripheral nerves and dorsal root ganglia. Anesthesiology 105:146-153.

Allt G and Lawrenson JG (2000) The blood-nerve barrier: enzymes, transporters and receptors-a comparison with the blood-brain barrier. Brain Res Bull 52:1-12.

Arvidson B (1979) A study of the perineurial diffusion barrier of a peripheral ganglion. Acta Neuropathol 46:139-144.

Bartanusz V, Jezova D, Alajajian B, and Digicaylioglu M (2011) The blood-spinal cord barrier: morphology and clinical implications. Ann Neurol 70:194-206.

Bell MA and Weddell AG (1984) A descriptive study of the blood vessels of the sciatic nerve in the rat, man and other mammals. Brain 107:871-898.

Davies B and Morris T (1993) Physiological parameters in laboratory animals and humans. Pharm Res 10:1093-1095.

Di L, Rong H, and Feng B (2013) Demystifying brain penetration in central nervous system drug discovery. Miniperspective. J Med Chem 56:2-12.

Di L, Umland JP, Chang G, Huang Y, Lin Z, Scott DO, Troutman MD, and Liston TE (2011) Species independence in brain tissue binding using brain homogenates. Drug Metab Dispos 39:1270-1277.

Dolgikh E, Watson IA, Desai PV, Sawada GA, Morton S, Jones TM, and Raub TJ (2016) QSAR model of unbound brain-to-plasma partition coefficient, $K_{\mathrm{p} \text {,uubrain }}$ incorporating P-glycoprotein efflux as a variable. J Chem Inf Model 56:2225-2233.
Ertl P, Rohde B, and Selzer P (2000) Fast calculation of molecular polar surface area as a sum of fragment-based contributions and its application to the prediction of drug transport properties. J Med Chem 43:3714-3717.

Hammarlund-Udenaes M, Fridén M, Syvänen S, and Gupta A (2008) On the rate and extent of drug delivery to the brain. Pharm Res 25:1737-1750.

Huang L, Li X, Roberts J, Janosky B, and Lin MH (2015) Differential role of P-glycoprotein and breast cancer resistance protein in drug distribution into brain, $\mathrm{CSF}$ and peripheral nerve tissues in rats. Xenobiotica 45:547-555.

Jacobs JM, Macfarlane RM, and Cavanagh JB (1976) Vascular leakage in the dorsal root ganglia of the rat, studied with horseradish peroxidase. J Neurol Sci 29:95-107.

Kanda T (2013) Biology of the blood-nerve barrier and its alteration in immune mediated neuropathies. J Neurol Neurosurg Psychiatry 84:208-212.

Kodaira H, Kusuhara H, Ushiki J, Fuse E, and Sugiyama Y (2010) Kinetic analysis of the cooperation of $\mathrm{P}$-glycoprotein (P-gp/Abcb1) and breast cancer resistance protein (Bcrp/Abcg2) in limiting the brain and testis penetration of erlotinib, flavopiridol, and mitoxantrone. $J$ Pharmacol Exp Ther 333:788-796.

Liem L, van Dongen E, Huygen FJ, Staats P, and Kramer J (2016) The dorsal root ganglion as a therapeutic target for chronic pain. Reg Anesth Pain Med 41:511-519. Liu H, Huang L, Li Y, Fu T, Sun X, Zhang YY, Gao R, Chen Q, Zhang W, Sahi J, et al. (2017) Correlation between membrane protein expression levels and transcellular transport activity for breast cancer resistance protein. Drug Metab Dispos 45:449-456.

Liu X, Chen C, and Smith BJ (2008) Progress in brain penetration evaluation in drug discovery and development. J Pharmacol Exp Ther 325:349-356.

Mahar Doan KM, Humphreys JE, Webster LO, Wring SA, Shampine LJ, SerabjitSingh CJ, Adkison KK, and Polli JW (2002) Passive permeability and P-glycoprotein-mediated efflux differentiate central nervous system (CNS) and non-CNS marketed drugs. J Pharmacol Exp Ther 303:1029-1037.

Matsson P,Pedersen JM, Norinder U, Bergström CA, and Artursson P (2009) Identification of novel specific and general inhibitors of the three major human ATPbinding cassette transporters P-gp, BCRP and MRP2 among registered drugs. Pharm Res 26:1816-1831.

Olsson Y (1971) Studies on vascular permeability in peripheral nerves. IV. Distribution of intravenously injected protein tracers in the peripheral nervous system of various species. Acta Neuropathol 17:114-126.

Peltonen S, Alanne M, and Peltonen J (2013) Barriers of the peripheral nerve. Tissue Barriers 1:e24956.

Poduslo JF, Curran GL, and Berg CT (1994) Macromolecular permeability across the blood-nerve and blood-brain barriers. Proc Natl Acad Sci USA 91:5705-5709.

Polli JW, Wring SA, Humphreys JE, Huang L, Morgan JB, Webster LO, and SerabjitSingh CS (2001) Rational use of in vitro P-glycoprotein assays in drug discovery. $J$ Pharmacol Exp Ther 299:620-628.

Rankovic Z (2015) CNS drug design: balancing physicochemical properties for optimal brain exposure. J Med Chem 58:2584-2608.

Rechthand E, Smith QR, and Rapoport SI (1987) Transfer of nonelectrolytes from blood into peripheral nerve endoneurium. Am J Physiol 252:H1175-H1182.

Rechthand E, Smith QR, and Rapoport SI (1988) A compartmental analysis of solute transfer and exchange across blood-nerve barrier. Am J Physiol 255:R317-R325.

Riccardi K, Cawley S, Yates PD, Chang C, Funk C, Niosi M, Lin J, and Di L (2015) Plasma protein binding of challenging compounds. J Pharm Sci 104:2627-2636.

Saito T, Zhang ZJ, Ohtsubo T, Noda I, Shibamori Y, Yamamoto T, and Saito H (2001) Homozygous disruption of the mdr1a P-glycoprotein gene affects blood-nerve barrier function in mice administered with neurotoxic drugs. Acta Otolaryngol 121:735-742.

Sapunar D, Kostic S, Banozic A, and Puljak L (2012) Dorsal root ganglion-a potential new therapeutic target for neuropathic pain. J Pain Res 5:31-38.

Schinkel AH, Wagenaar E, Mol CA, and van Deemter L (1996) P-glycoprotein in the blood-brain barrier of mice influences the brain penetration and pharmacological activity of many drugs. J Clin Invest 97:2517-2524.

Seitz RJ, Heininger K, Schwendemann G, Toyka KV, and Wechsler W (1985) The mouse blood-brain barrier and blood-nerve barrier for IgG: a tracer study by use of the avidin-biotin system. Acta Neuropathol 68:15-21.

Summerfield SG, Lucas AJ, Porter RA, Jeffrey P, Gunn RN, Read KR, Stevens AJ, Metcalf AC, Osuna MC, Kilford PJ, et al. (2008) Toward an improved prediction of human in vivo brain penetration. Xenobiotica 38:1518-1535.

Summerfield SG, Read K, Begley DJ, Obradovic T, Hidalgo IJ, Coggon S, Lewis AV, Porter RA, and Jeffrey P (2007) Central nervous system drug disposition: the relationship between in situ brain permeability and brain free fraction. $J$ Pharmacol Exp Ther 322:205-213.

Summerfield SG, Zhang Y, and Liu H (2016) Examining the uptake of central nervous system drugs and candidates across the blood-brain barrier. J Pharmacol Exp Ther 358:294-305.

Thiel-Demby VE, Humphreys JE, St John Williams LA, Ellens HM, Shah N, Ayrton $\mathrm{AD}$, and Polli JW (2009) Biopharmaceutics classification system: validation and learnings of an in vitro permeability assay. Mol Pharm 6:11-18

von Richter O, Glavinas H, Krajcsi P, Liehner S, Siewert B, and Zech K (2009) A novel screening strategy to identify ABCB1 substrates and inhibitors. Naunyn Schmiedebergs Arch Pharmacol 379:11-26.

Weerasuriya A and Mizisin AP (2011) The blood-nerve barrier: structure and functional significance. Methods Mol Biol 686:149-173.

Yosef N and Ubogu EE (2013) An immortalized human blood-nerve barrier endothelial cell line for in vitro permeability studies. Cell Mol Neurobiol 33:175-186.

Yosef N, Xia RH, and Ubogu EE (2010) Development and characterization of a novel human in vitro blood-nerve barrier model using primary endoneurial endothelial cells. J Neuropathol Exp Neurol 69:82-97.

Address correspondence to: Dr. Houfu Liu, GlaxoSmithKline R\&D China, 898 Halei Road, Zhangjiang Hi-Tech Park, Shanghai 201203, People's Republic of China. E-mail: liuhoufu79@hotmail.com 